\title{
Bentuk Hunian Informal: Studi Kasus tentang Hunian Bertahap di Kampung Melayu Semarang
}

\section{The Forms of Informal Settlements: A Case Study of Incremental Housing in Kampung Melayu Semarang}

\author{
Desmalinda Kurniati Daraz $^{\text {a }}$, Wakhidah Kurniawati ${ }^{\text {b }}$ \\ ${ }^{a}$ Universitas Diponegoro, Semarang, Indonesia \\ ${ }^{b}$ Universitas Diponegoro, Semarang, Indonesia
}

\begin{abstract}
Abstrak
Permukiman informal mendominasi struktrur kota di dunia dan menjadi tempat tinggal bagi mayoritas penduduk kota. Selama lebih dari 50 tahun sudah dilakukan upaya untuk menghadapi keberadaan hunian informal, tetapi tantangan hunian informal tidak bisa diatasi hanya dengan penggusuran. Pemerintah telah berupaya melakukan peningkatan kualitas fisik hunian informal di Kampung Melayu Semarang melalui program KOTAKU yang berfokus pada penataan kawasan hunian agar sesuai dengan standar yang ditetapkan. Program tersebut seharusnya juga dapat mengakomodasi kebutuhan spasial penduduk, sehingga perlu untuk memahami lokasi secara mendalam yang dapat dilihat dari bentuk penyediaan huniannya. Penelitian ini bertujuan untuk mengkaji bentuk hunian informal di Kampung Melayu yang berfokus pada hunian informal di Jalan Melayu Tengah. Metode penelitian yang digunakan adalah kualitatif dengan teknik pengumpulan data melalui wawancara, observasi, dan dokumentasi. Data dianalisis menggunakan teknik analisis isi dan analisis deskriptif. Penelitian ini dapat menambah pengetahuan bagi pembaca dan bagi pemerintah terkait bentuk desain hunian informal di Kampung Melayu Semarang, sehingga menjadi masukan bagi perencanaan dan pembangunan yang lebih baik dan sesuai dengan kebutuhan penghuni. Hasil menunjukkan bahwa bentuk desain hunian informal di Kampung Melayu yaitu menambah ruang, menempelkan, mengganti dan menggabungkan, membagi ruang, dan menghubungkan ruang.
\end{abstract}

Kata kunci: Hunian Bertahap; Hunian Informal; Kondisi Hunian; Ruang Publik.

\begin{abstract}
Informal settlements dominate the structures of cities in the world and become the residence for urban residents. For more than 50 years efforts have been made to deal with the existence of informal settlements, but the challenges of informal settlements cannot be overcome simply by eviction. The Government has made efforts to improve the physical quality of informal settlement in Kampung Melayu Semarang through the KOTAKU program which focuses on managing settlements to conform with the predetermined standards. The program should accommodate the spatial needs of the population so that it is necessary to understand the location in depth to be able to find out the spatial needs of the population as seen from the housing provision form. This study aims to examine the form of informal settlements in Kampung Melayu which focuses on informal settlements on Melayu Tengah street. The research method used is qualitative which collecting data through interview, observation and documentation. Data were analyzed using content analysis and descriptive analysis. This research can improve the readers and government knowledge regarding the form of informal design, so that it becomes input for better planning and development that relevant to the needs of resident. The results show that the form of informal settlement in Kampung Melayu Semarang are done by extending space, attaching, replacing and infilling, deviding space, and connecting space.
\end{abstract}

Keyword: Incremental Housing; Informal Settlements; Housing Condition; Public Space. 


\section{Pendahuluan}

Hunian informal mengakomodasi setidaknya 1 milyar orang di dunia, dimana lebih dari 60\% kawasan hunian di Sub-Sahara Afrika dan Asia merupakan informal. Hunian informal telah menjadi tantangan selama 50 tahun terakhir dan telah dilakukan upaya peningkatan yang berfokus untuk menciptakan kawasan yang sesuai dengan standar. Akan tetapi, kondisi yang ada di hunian informal tidak dapat diatasi dengan mudah hanya dengan penggusuran ataupun pemindahan. (Kamalipour \& Dovey, 2019) dalam penelitiannya mengemukakan berbagai bentuk konstruksi hunian informal terbentuk atas upaya penduduk untuk meningkatkan kondisi huniannya secara bertahap. Saroj et al., (2019) juga menyebutkan jika penduduk di hunian informal cenderung membangun huniannya sendiri sesuai dengan gaya hidupnya, yang kemudian menghasilkan lingkungan hunian yang tidak teratur.

Kampung Melayu Semarang terletak di Kelurahan Dadapsari, Kecamatan Semarang Utara. Kampung Melayu telah berkembang sejak abad ke-17 dengan mengikuti struktur kota di zaman kolonial yang terbagi atas etnis-etnis (Wihardyanto \& Ikaputra, 2019). Terdapat 17\% hunian informal di Kampung Melayu masih belum memiliki hak milik dan masih terdapat juga $29 \%$ bangunan rumah semi permanen dan $6 \%$ bangunan rumah non-permanen. Penelitian terdahulu oleh Febbiyana \& Suwandono (2016), menunjukkan bahwa sebagian besar lingkungan hunian di Kampung Melayu cenderung terkesan sempit dan kurang akan tempat publik dan Ruang Terbuka Hijau. Hunian informal yang dihuni oleh penduduk pendatang, tidak memiliki hak milik, dan dibangun menggunakan material yang belum permanen dapat ditemukan di sepanjang Jalan Melayu Tengah.

Pemerintah Kota Semarang telah berupaya melakukan peningkatan kualitas fisik di Kampung Melayu Semarang melalui program Kota Tanpa Kumuh (KOTAKU) yang berfokus pada peningkatan kualitas fisik lingkungan untuk mengatasi hunian kumuh yang tidak layak huni karena ketidakteraturan bangunan, tingkat kepadatan bangunan yang tinggi, dan kualitas bangunan serta sarana dan prasarana yang tidak memenuhi syarat. Program tersebut berupaya untuk mengatur dan menata kawasan agar sesuai dengan standar yang telah ditetapkan. Akan tetapi, program tersebut seharusnya tidak hanya mengatur dan menata kawasan saja, tetapi juga dapat mengakomodasi kebutuhan spasial penduduk sebagaimana yang disebutkan oleh Bhatt et al., (1990), jika upaya peningkatan kualitas permukiman informal perlu lebih mengakomodasi kebutuhan spasial penduduk daripada menciptakan kawasan yang sesuai dengan standar. Mengingat bahwa kondisi spasial di hunian informal terbentuk dari adanya proses peningkatan hunian secara bertahap yang didasari pada kebutuhan spasial penduduk. Proses peningkatan hunian yang tanpa disertai dengan perencanaan ini dapat menghasilkan kawasan yang kumuh (Kamalipour, 2020). Untuk itu perlu adanya pengkajian mendalam tentang bentuk hunian bertahap yang dilakukan oleh penduduk di Kampung Melayu dengan mempertimbangkan kecenderungan ruang yang fleksibel dan dinamis, yang berubah sesuai dengan kebutuhan spasial penduduk.

Penelitian yang bertujuan untuk mengkaji bentuk hunian bertahap Kampung Melayu Semarang ini berfokus pada hunian di sepanjang Jalan Melayu Tengah, sebagai representasi dari hunian informal di Kampung Melayu. Rumah di Jalan Melayu Tengah menjadi fokus penelitian karena tidak memiliki hak milik dan tidak termasuk dalam sejarah perkembangan Kampung Melayu, penduduk melakukan peningkatan bertahap pada huniannya yang mengokupansi ruang Jalan Melayu Tengah dan ruang drainase. Terdapat 22 rumah informal yang didirikan oleh para penduduk pendatang di sepanjang Jalan Melayu Tengah. Hunian informal di Jalan Melayu Tengah berkembang secara spontan karena kedatangan penduduk dari luar yang menetap lama hingga generasi berikutnya. Perkembangan hunian awalnya hanya berupa bedeng sebagai hunian sementara dan kemudian hunian tersebut semakin berkembang dengan sendirinya. Penduduk tidak memiliki hak milik atas lahan hunian, rumah hunian didirikan illegal dengan menempel pada bagian belakang bangunan rumah milik etnis Tionghoa yang sudah tidak ditempati. 


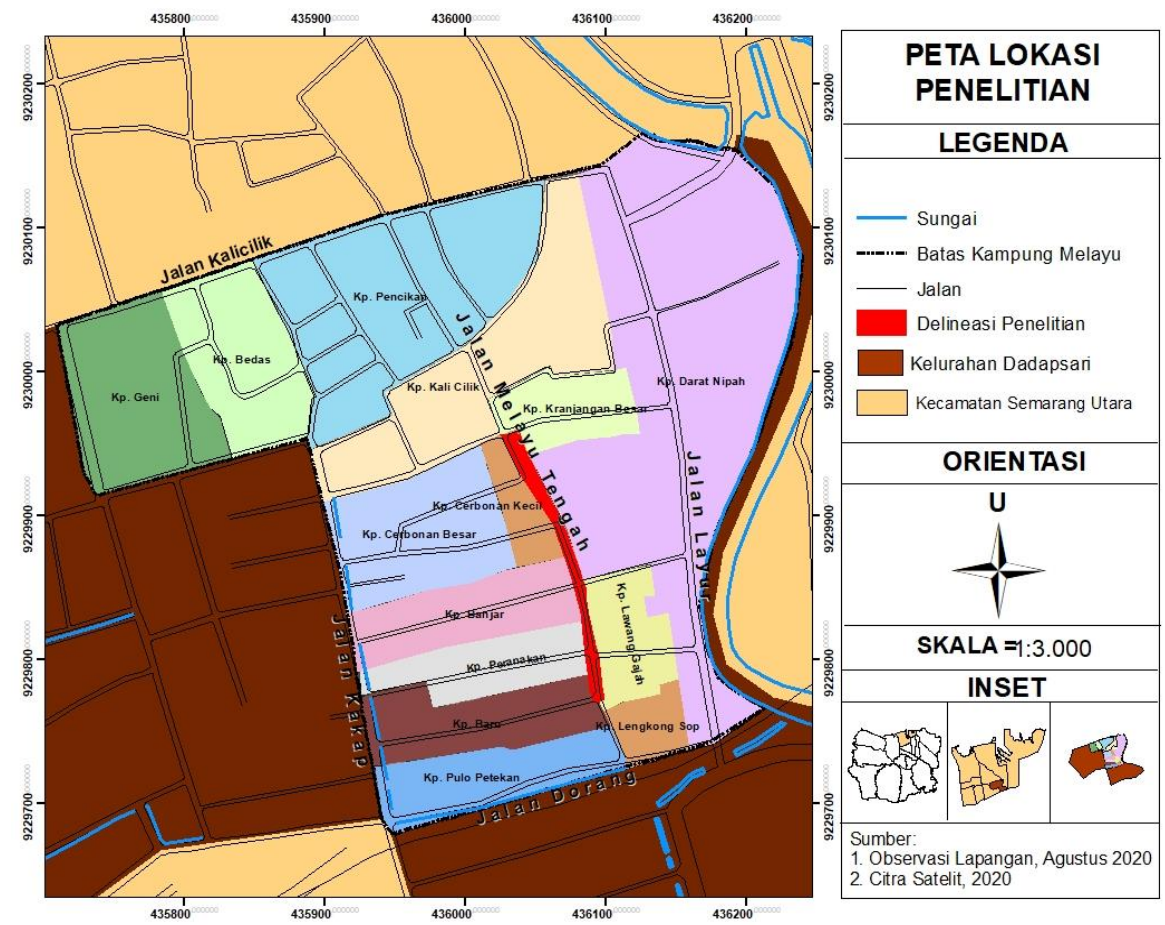

Gambar 1. Peta Lokasi Penelitian (Citra Google Earth, 2020)

\section{Metode}

Metode yang digunakan dalam penelitian ini adalah deskriptif kualitatif. Objek penelitian adalah hunian informal yang berada di Jalan Melayu Tengah. Pengambilan sampel dilakukan dengan cara purposive dan memerlukan adanya keterlibatan langsung antara peneliti dan narasumber untuk mendapatkan data dan informasi yang lebih representatif. Pemilihan narasumber dilakukan atas dasar apa yang diketahui oleh objek penelitian yang sesuai dengan kebutuhan penelitian (Kustiawan \& Ramadhan, 2019). Adapun narasumber dalam penelitian ini berjumlah 7 orang yang terdiri dari 5 penduduk di hunian informal di Jalan Melayu Tengah, 1 orang pegawai kantor Kelurahan Dadapsari yang terlibat dalam program Kampung Melayu, dan Lurah Dadapsari. Teknik pengumpulan data dalam penelitian ini menggunakan teknik pengumpulan data primer melalui wawancara dan observasi lapangan, dan teknik pengumpulan data sekunder yang dilakukan dengan kajian literatur dan telaah dokumen. Data terkumpul akan dianalisis menggunakan teknik analisis isi dan analisis deskriptif kualitatif.

\section{Kajian Literatur}

\subsection{Kampung}

Kampung merupakan suatu kawasan di dalam kota yang masih mempertahankan kebudayaan sebelumnya, baik fisik berupa bangunan tradisional maupun kegiatan yang telah ada sejak dahulu yang masih dilakukan hingga sekarang (Devi, Lowry, \& Weber, 2017). Kampung hunian sementara (temporary squatter kampong) merupakan salah satu tipe kampung yang letaknya tersebar di kawasan metropolitan dan memiliki kondisi terburuk dimana tidak tersedia fasilitas, tidak memiliki status kepemilikan lahan dan biasanya menghadapi banyak desakan ekonomi. Mayoritas penduduk merupakan migran dari kawasan perdesaan atau pinggiran dimana kondisi penduduknya berubah dari waktu ke waktu tergantung adanya transformasi sosial perkotaan dan rentan akan adanya penggusuran. Bentuk kampung hunian sementara juga mengikuti trend perkembangan kota di sekitarnya. Istilah kampung juga digunakan untuk menjelaskan fenomena hunian di perkotaan yang dibangun secara mandiri oleh penduduk pendatang. Hunian ini memiliki karakteristik seperti kampung di perdesaan, tapi berada di kawasan kota, yang disebut dengan istilah kampung kota. Kampung kota merupakan bentuk hunian informal yang dibangun masyarakat secara mandiri dan biasanya berlokasi di pusat kota (Kristian \& Yuliastuti, 2013). 


\subsection{Hunian Informal (Informal Settlements), Perkembangan dan Karakteristiknya}

Hunian informal adalah kawasan hunian dimana penduduknya tidak memiliki hak legal atas lahan, konstruksinya tidak memenuhi standar keamanan, bangunan rumah memiliki kondisi yang buruk, serta mengalami kekurangan infrastruktur dan ruang terbuka (Un-Habitat, 2015). Bentuk-bentuk kegiatan pembangunan yang ada di hunian informal seringkali tidak memperhitungkan aturan pembangunan yang ada. Hunian informal tidak mengindahkan adanya kebutuhan masyarakat akan kesehatan, lingkungan, pencahayaan, dan building regulations (Lombard, 2016). Hunian informal juga tidak memperhitungkan kaidah- kaidah standar perencanaan seperti kepadatan bangunan, jaringan jalan, dan ketersediaan fasilitas (Alzamil, 2018). Kurangnya perencanaan menyebabkan kawasan hunian informal menghadapi masalah ketersediaan fasilitas pelayanan, selain itu hunian informal seringkali mengokupansi ruang terbuka untuk menciptakan ruang hunian (Msimang, 2017).

Bentuk dominan dari perkembangan hunian di hunian informal adalah bertahap (incremental) dan "self organized", dimana bangunan berkembang karena adanya penambahan ruang hunian secara mandiri oleh penghuninya atau dengan mengokupansi suatu tempat untuk menambah ruang huniannya (Kamalipour \& Dovey, 2019). Penduduk di hunian informal membangun huniannya sesuai dengan kebutuhan dan kemampuannya, yang dapat dikenali dari konstruksi bertahap dan menggunakan material non formal seperti bata, bambu, dan kayu (Saroj et al., 2019). Informasi tentang karakteristik fisik kawasan dilihat dari fasilitas yang ada. Kondisi hunian dilihat dari dinding, lantai, atap, dan kondisi keseluruhan yang nampak pada hunian juga sejauh mana tingkat kerusakan yang ada. Penilaian ini dapat dilakukan dengan observasi visual. Karakteristik hunian informal adalah memiliki kekurangan fasilitas dasar, seperti fasilitas pembuangan sampah; jaringan jalan, toilet, dan saluran drainase yang tertutupi hunian; kurangnya akses terhadap air bersih, dan kondisi sanitasi yang buruk (Msimang, 2017).

\subsection{Hunian Bertahap}

Penduduk di hunian informal cenderung melakukan peningkatan secara bertahap pada huniannya bertujuan untuk meningkatkan efisiensi dengan tetap mempertahankan atribut utama hunian. Peningkatan hunian secara bertahap ini bertujuan untuk meningkatkan efisiensi pada sistem hunian eksisting. Beberapa bentuk hunian bertahap yang dilakukan dapat berupa penambahan ruang-ruang kamar, penambahan balkon dan teras, serta penambahan tangga dan perluasan atap bangunan. Chhetri et al., (2019) menjelaskan, bentuk hunian bertahap yang dilakukan penduduk dapat dilakukan dengan cara addition (membangun ruang baru) dan dapat dilakukan dengan renovation (melakukan perubahan pada ruang yang sudah ada) antara lain dengan extend (memperluas), attach (menempelkan), replace (mengganti), divide (membagi), infill (menggabungkan), dan connect (menghubungkan). Hasgül (2016) menyatakan, perubahan secara bertahap yang dilakukan penduduk di hunian informal disebabkan oleh faktor ekonomi dan sosial. Dovey (2015) menyebutkan, aktivitas sosial berupa interaksi antar penduduk di hunian informal dapat berpengaruh terhadap kondisi ruang publik karena sangat bergantung pada kapasitas ruang publik untuk menunjang kegiatan yang berlangsung di dalamnya.

\section{Hasil dan Pembahasan}

Berdasarkan hasil observasi dan wawancara, dari total jumlah 22 rumah di Jalan Melayu Tengah, terdapat 5 rumah yang dibangun dengan material permanen yaitu batu bata dan semen secara keseluruhan, sedangkan 17 rumah penduduk melakukan pencampuran material non permanen dan material permanen seperti batu bata untuk dinding rumah, kayu untuk pintu dan jendela, semen untuk lantai, serta konstruksi atap menggunakan asbes. Perubahan material bangunan dari non-permanen menjadi permanen juga dilakukan penduduk guna meningkatkan kondisi rumahnya. Terdapat juga upaya perbaikan dan peninggian atap untuk menutupi lubang pada atap dan juga untuk menciptakan lebih banyak ruang sirkulasi udara. Kondisi hunian memiliki luas yang berbeda-beda. Bangunan hunian di Jalan Melayu Tengah hampir seluruhnya memiliki luas lantai kurang dari $36 \mathrm{~m}^{2}$. Hanya terdapat 1 rumah yang memiliki luas lebih dari $36 \mathrm{~m}^{2}$ karena bangunan tersebut merupakan bangunan tua. Rumah di Jalan Melayu Tengah paling sedikit ditempati oleh 3 orang, yang berarti kurang dari standar maksimal 1 rumah ditempati oleh 5 orang jumlah anggota keluarga. Dengan demikian, luas lantai bangunan di Jalan Melayu Tengah masih tergolong sesuai dengan standar teknis bangunan yang ada. 
Berdasarkan data NUSP-2 (2017) kondisi jalan lingkungan di Kampung Melayu yang memiliki lebar 5,2 meter tergolong kurang baik dan kondisinya rusak dengan rata-rata terbuat dari material paving dan aspal. Meskipun jalan termasuk lebar, namun karena okupansi rumah dan aktivitas penduduk menjadikan ruang sirkulasi kendaraan berkurang menjadi hanya selebar 2,4 meter yang menyebabkan jalan ini terkesan sempit dan kurang nyaman dilalui. Untuk ketersediaan air bersih, penduduk Jalan Melayu Tengah mendapatkan sumber air dari sumur, hidran umum dan PDAM. Namun penduduk lebih memilih menggunakan air sumur karena gratis meskipun kondisi air sumur masih belum memenuhi standar karena kondisinya tercemar dan berwarna keruh kekuningan.

Berdasarkan data NUSP-2 (2017), pengelolaan air limbah rumah tangga di Kampung Melayu masih bercampur menjadi satu dan dibuang ke saluran drainase. Penduduk di Jalan Melayu Tengah kebanyakan sudah memiliki jamban pribadi. Terdapat juga rumah yang belum memiliki jamban dan menggunakan MCK bersama-sama untuk dua rumah yang penghuninya masih ada hubungan keluarga. Penduduk memanfaatkan lahan sisa dari ruang jalan dan drainase yang ada di sekitar rumah untuk membangun MCK. Limbah dari MCK akan langsung disalurkan ke drainase, karena rumah-rumah di Jalan Melayu Tengah tidak memiliki septik tank. Toilet umum yang ada di Jalan Melayu Tengah juga tidak memiliki septictank, sehingga limbahnya langsung dibuang ke saluran drainase.

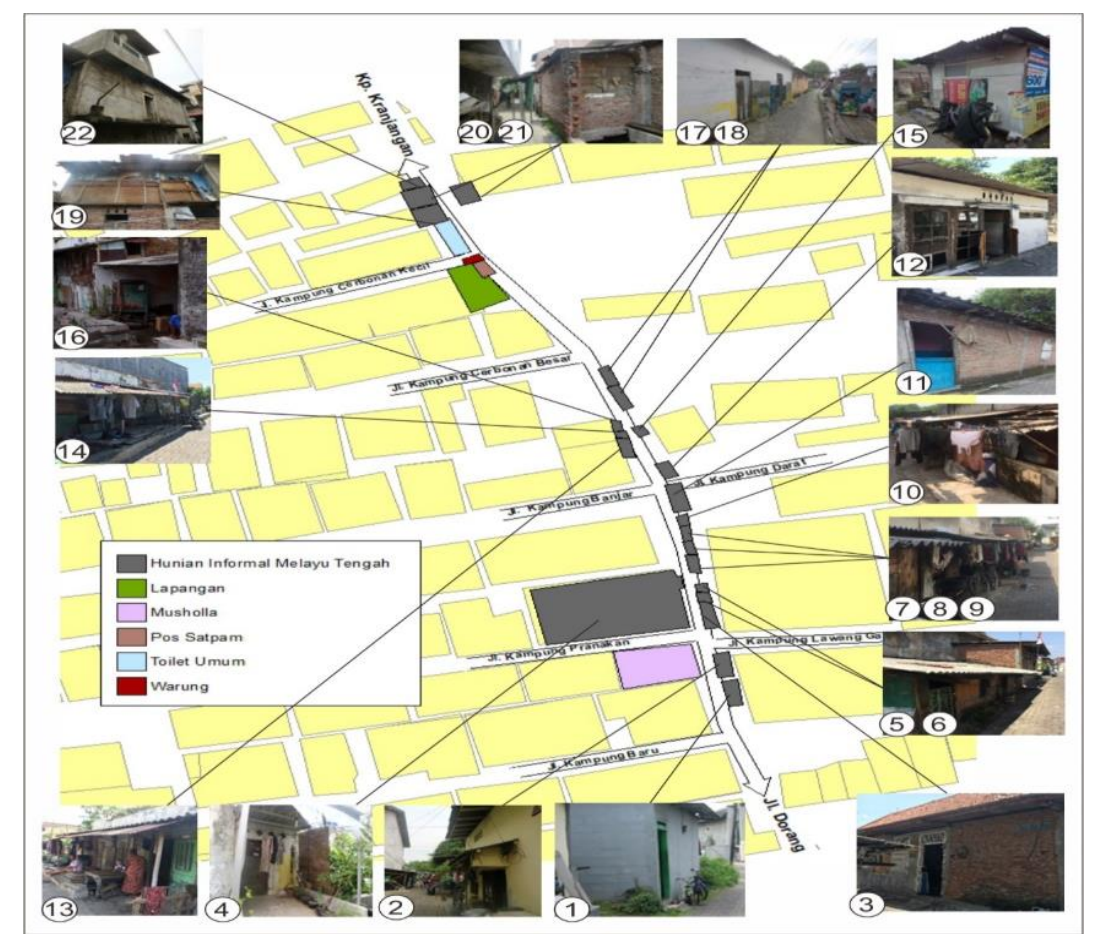

Gambar 2. Lokasi Hunian Informal di Jalan Melayu Tengah (Dokumentasi Peneliti, 2020)

Kondisi jaringan persampahan di Kampung Melayu memiliki kondisi yang belum memenuhi standar NUSP-2 (2017). Terdapat perilaku membuang sampah dan limbah di pekarangan, sungai, drainase, atau dibakar dan belum ada pengelolaan sampah yang baik di Kampung Melayu. Telah dilakukan pengangkutan sampah rumah tangga ke TPS (Tempat pembuangan sampah sementara), tetapi belum terjadwal. Pengangkutan sampah yang ada belum teratur dan biasanya diangkut seminggu sekali atau bahkan dua minggu sekali. Hal ini menjadikan kawasan di Jalan Melayu Tengah terlihat kotor karena sampah yang berserakan dan seringkali terbawa angin kemudian jatuh ke drainase, menyebabkan saluran drainase penuh akan sampah. Untuk infrastruktur drainase, terdapat saluran drainase yang cukup besar di Jalan Melayu Tengah dengan lebar mencapai 1,5 meter. Berdasarkan wawancara dengan penduduk, tidak ada kejadian genangan di Jalan Melayu Tengah sejak adanya program peninggian jalan dari pemerintah. Akan tetapi, kondisi drainase di Jalan Melayu Tengah alirannya dicemari oleh limbah cair dari MCK penduduk dan sampah yang menyebabkan air di saluran drainase berwarna hijau kehitaman dan berbau tidak sedap. Kondisi yang demikian diperburuk dengan tidak dapat dibersihkannya drainase karena rumah penduduk yang didirikan di atas saluran 
drainase sehingga menutup saluran. Dari keseluruhan hasil terkait jaringan infrastruktur dan kondisi fasilitas, kawasan hunian informal di Jalan Melayu Tengah masih belum memenuhi standar. Lokasi hunian informal di Jalan Melayu Tengah dapat dilihat pada Gambar 2.

Ruang publik di Jalan Melayu Tengah terbatas pada ruang infrastruktur jaringan jalan dan drainase. Ruang drainase telah diokupansi oleh beberapa rumah penduduk yang didirikan di atasnya. Hal ini menjadikan drainase tidak dapat dibersihkan dan menjadi kotor. Selain itu, kendaraan-kendaraan yang diparkir di depan rumah penduduk juga mengokupansi ruang jalan dan menyebabkan jalanan menjadi semakin sempit. Sejalan dengan hasil penelitian Nguluma (2003) yang menyimpulkan bahwa hunian informal memiliki karakteristik sebagai kawasan yang berkembang tanpa mengikuti standar konstruksi yang ada, sehingga mengalami kekurangan fasilitas dasar seperti air bersih, jaringan jalan, sanitasi, saluran drainase, sistem pembuangan, dan juga sistem sanitasi. Kondisi seperti ini dapat menjadi lebih buruk oleh adanya upaya penduduk untuk meningkatkan huniannya. Seperti halnya menurut (Kamalipour \& Dovey, 2020), bahwa hunian informal terbentuk oleh adanya proses peningkatan bertahap yang dapat menyebabkan terjadinya kawasan slum (kumuh). Selanjutnya akan dipaparkan hasil dan pembahasan terkait proses perubahan bertahap hunian informal yang terdapat di Jalan Melayu Tengah, yaitu bentuk konstruksi hunian bertahap dan okupansi ruang oleh hunian bertahap untuk mendapatkan pemahaman yang lebih baik terhadap bentuk hunian bertahap di Kampung Melayu Semarang.

\subsection{Bentuk Hunian Bertahap di Jalan Melayu Tengah Kampung Melayu Semarang}

Hunian informal selalu berada dalam proses perubahan secara bertahap yang dapat dikenali dari karakteristik bentuk hunian penduduk yakni dari adanya peningkatan bertahap cara addition (membangun ruang baru) dan cara renovation (melakukan perubahan pada ruang yang sudah ada) (Kamalipour \& Dovey, 2020). Di hunian informal di Jalan Melayu Tengah, dapat ditemukan berbagai bentuk hunian bertahap yang telah dilakukan penduduk antara lain:

1. Menambah ruang hunian dengan cara vertikal dan horizontal seperti penambahan fasilitas dapur, penambahan toilet dan ruang penyimpanan, penambahan teras, penambahan ruang aktivitas, dan penambahan jumah lantai rumah. Penambahan ruang ini dilakukan dengan cara memperluas ruang eksisting atau dengan menambah bangunan baru pada bangunan rumah eksisting. Proses ini mirip seperti peroses "extend" dalam penelitian (Kamalipour \& Dovey, 2020), dimana penghuni rumah melakukan penambahan ruang hunian secara horizontal. Ketika pertumbuhan ruang horizontal sudah mencapai titik jenuh (sudah tidak tersedia ruang lagi) maka penambahan ruang akan dilakukan secara vertikal. Penambahan ruang dilakukan dengan mengokupansi ruang jalan dan ruang drainase yang ada di sekitar Jalan Melayu Tengah. Berikut merupakan hasil observasi bentuk hunian penduduk yang melakukan penambahan ruang (Gambar 3).
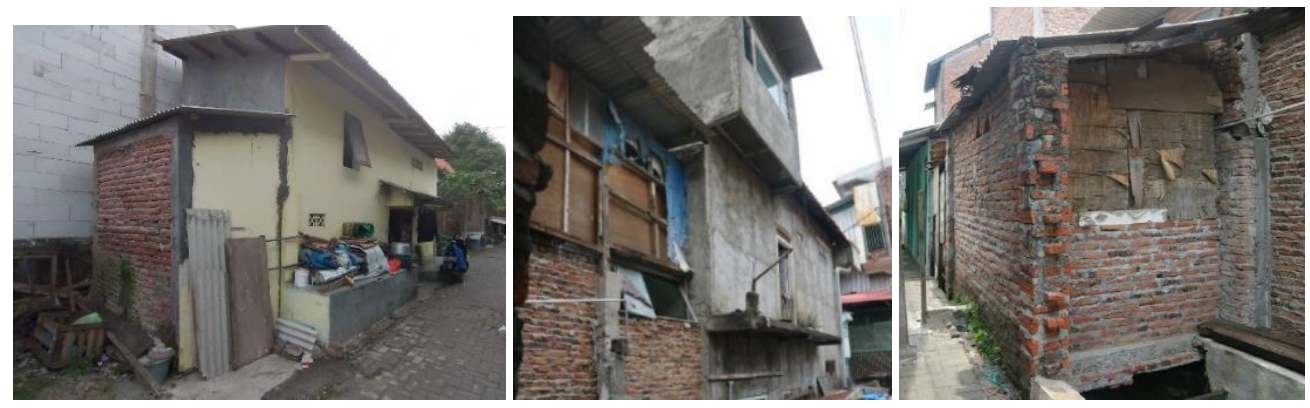

Gambar 3. Hunian yang Melakukan Penambahan Luas (Analisis Peneliti, 2020)

2. Menempelkan bagian baru pada hunian dilakukan dengan penambahan atap, penambahan beranda dan penambahan teras pada bangunan eksisting. Penambahan ini dimaksudkan untuk membuat ruang baru pada hunian seperti membuat tempat untuk meletakkan tanaman hias, dan untuk menutupi saluran drainase yang ada di bawahnya. Hunian penduduk yang melakukan penempelan bagian baru dapat dilihat pada Gambar 4. 


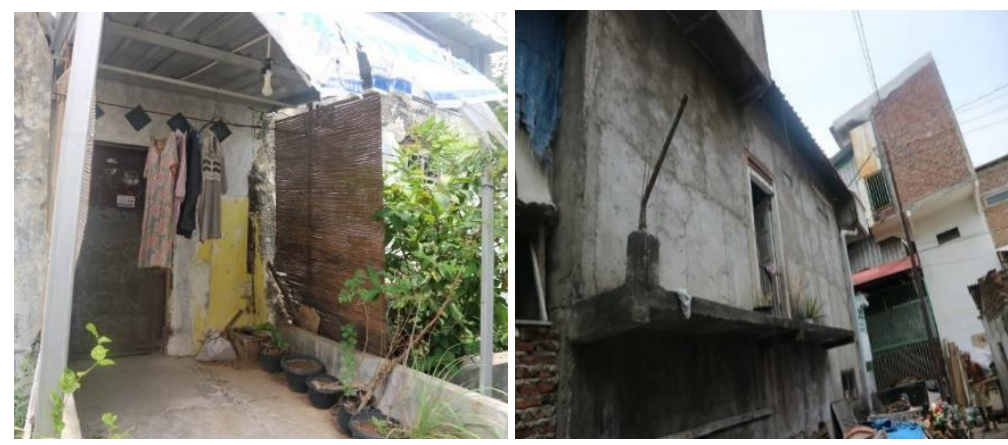

Gambar 4. Hunian yang Melakukan Perluasan dengan Menempel Bagian Baru (Analisis Peneliti, 2020)

3. Mengganti dan menggabungkan material untuk meningkatkan kualitas konstruksi dan menambah image bangunan eksisting. Penggantian material juga dimaksudkan untuk meningkatkan kenyamanan bagi penghuninya. Hal ini adalah proses peningkatan informal dimana penghuni mengganti material yang non-permanen seperti triplek dan seng dengan material yang lebih permanen seperti batu bata dan asbes. Terdapat juga proses pengecatan rumah untuk meningkatkan estetika bangunan. Sisa material yang digunakan biasanya diletakkan di ruang kosong sekitar rumah untuk nantinya dapat digunakan lagi jika ingin melakukan peningkatan hunian di masa depan. Hunian penduduk yang melakukan penggantian dan penggabungan material dapat dilihat pada Gambar 5.
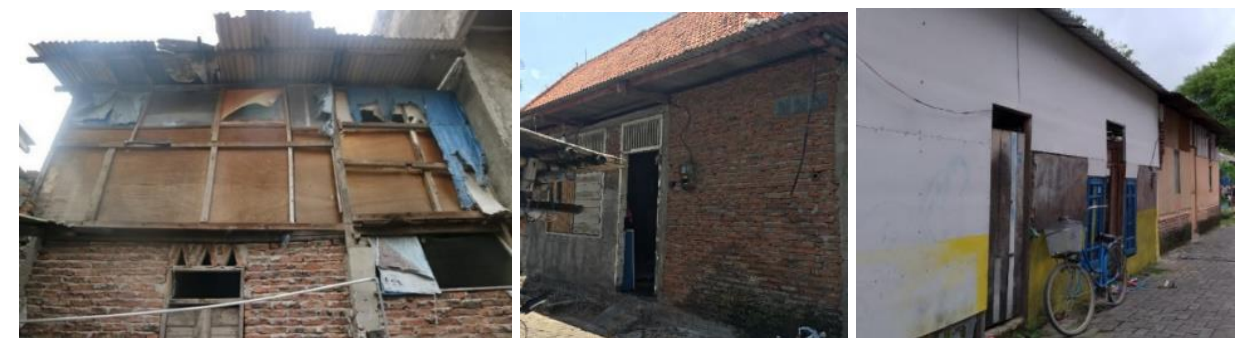

Gambar 5. Hunian yang Melakukan Penggantian dan Penggabungan Material (Analisis Peneliti, 2020)

4. Membagi fungsi ruang hunian berdasarkan aktivitas penduduk. Penduduk memanfaatkan ruang sisa semaksimal mungkin untuk kegiatan aktivitasnya, semakin beragam aktivitas penduduk maka semakin banyak ruang yang dibutuhkan untuk aktivitas tersebut. Sebagai contoh rumah salah seorang penduduk yang mulanya memiliki 2 ruang aktivitas sekarang terbagi menjadi 3 ruang karena bekerja dari rumah. Hunian penduduk yang melakukan pembagian fungsi ruang dapar dilihat pada Gambar 6.

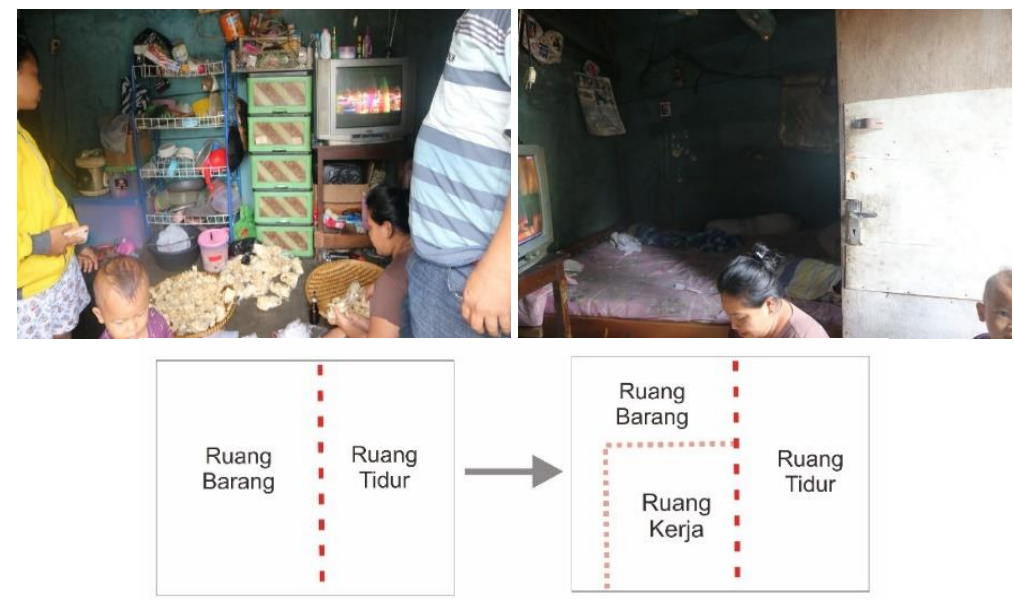

Gambar 6. Hunian yang Melakukan Pembagian Ruang (Analisis Peneliti, 2020)

5. Menghubungkan hunian dengan jaringan infrastruktur yakni dengan menciptakan hubungan antara hunian dan fasilitas publik. Bentuk hunian bertahap ini dapat ditemukan pada semua rumah di Jalan Melayu Tengah yang menghubungkan hunian dengan jalan dan drainase. 
Hunian penduduk yang menghubungkan dengan jaringan infrastruktur dapat dilihat pada Gambar 7.

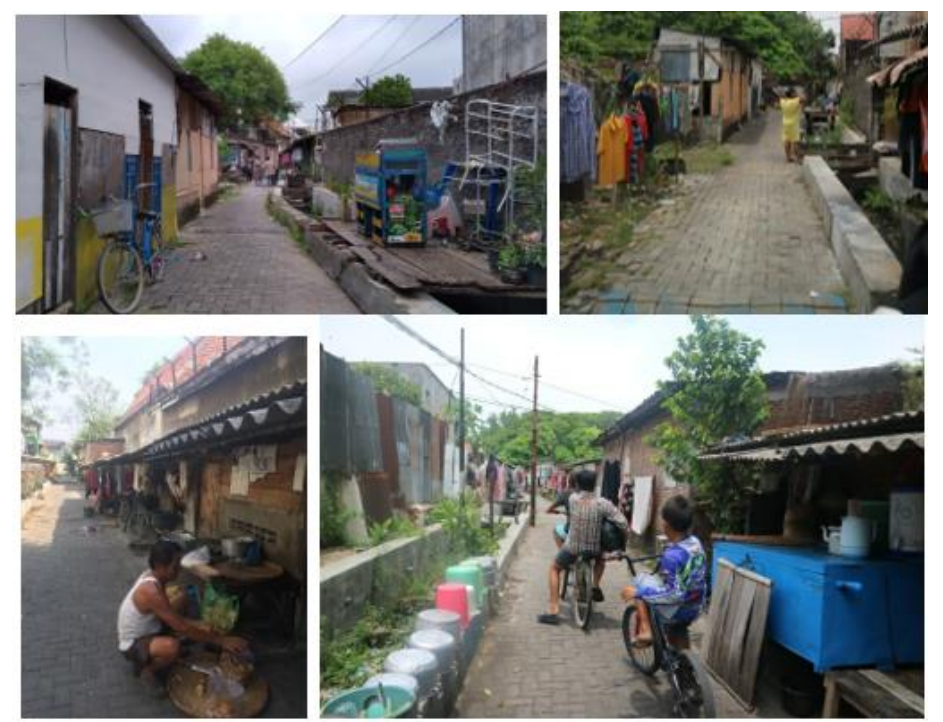

Gambar 7. Hunian yang Menghubungkan dengan Jaringan Publik (Analisis Peneliti, 2020)

Berbagai bentuk hunian bertahap ditemukan di hunian informal di Jalan Melayu Tengah. Proses hunian bertahap yang dilakukan dalam satu rumah bisa jadi tidak hanya satu, tetapi merupakan kombinasi dari dua bahkan tiga proses. Semua rumah yang ada di Jalan Melayu Tengah telah diubah materialnya dan terhubung dengan fasilitas publik jaringan jalan dan drainase, sebagian rumah telah melakukan perluasan ruang untuk fasilitas, sebagian rumah juga melakukan penempelan bagian baru pada hunian seperti penempelan abgian atap baru, pembuatan teras, serta beranda. Hanya terdapat 1 rumah yang diketahui melakukan pembagian fungsi ruang karena adanya perubahan aktivitas di dalam rumah. Bentuk hunian informal yang ada di Jalan Melayu ini dapat memberikan pengaruh terhadap lingkungan di sekitarnya, karena adanya okupansi terhadap ruang publik dan ruang drainase.

\subsection{Okupansi Ruang Oleh Konstruksi Hunian Bertahap}

Konstruksi rumah di Jalan Melayu Tengah dibangun berdasarkan kebutuhan penghuninya. Penduduk menggunakan ruang publik yang terbatas untuk ruang hidupnya dengan sangat efektif. Tidak hanya mengokupansi ruang untuk aktvitas saja, tetapi juga untuk ruang rumah. okupansi ruang oleh konstruksi hunian bertahap di Jalan Melayu Tengah yang dilakukan penduduk antara lain okupansi ruang dapur, okupansi ruang untuk mengolah makanan, okupansi ruang teras, okupansi ruang MCK, dan okupansi ruang untuk menyimpan barang. Lokasi okupansi hunian dapat dilihat pada Gambar 8. 


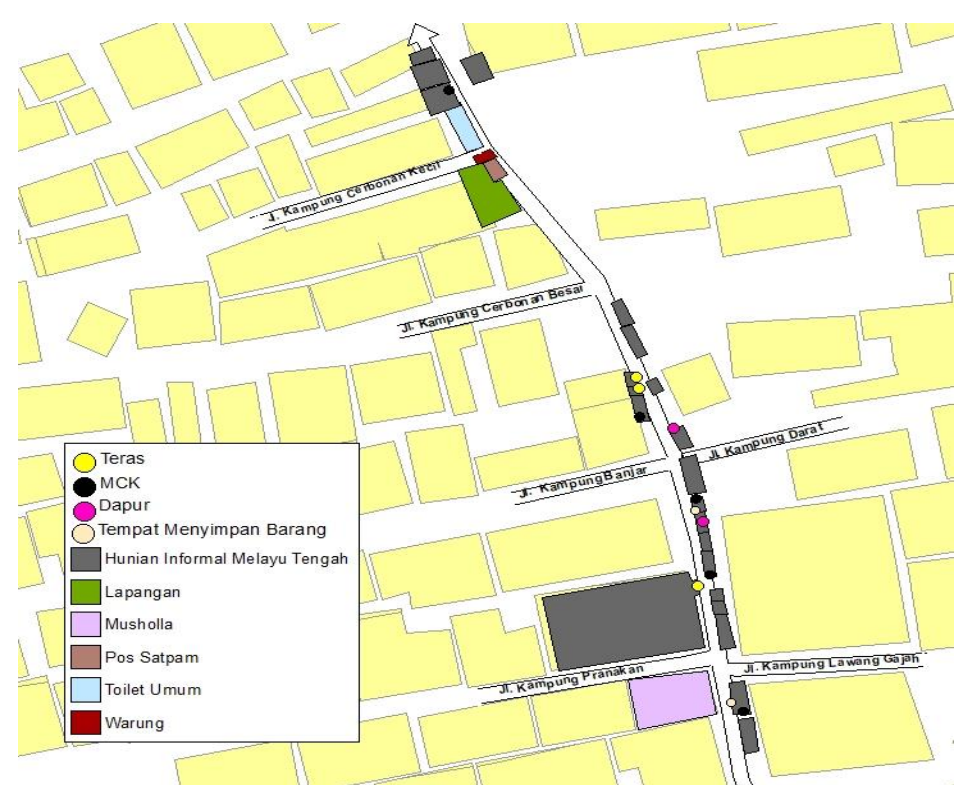

Gambar 8. Titik Lokasi Okupansi Hunian Bertahap di Jalan Melayu Tengah (Observasi Peneliti, 2020)

\subsection{Bentuk Hunian Informal di Jalan Melayu Tengah}

Hunian penduduk mayoritas melakukan pencampuran material permanen dan non permanen berupa kayu, asbes, batu bata, dan semen. Luas lantai hunian sudah sesuai dengan standar karena mencukupi luas minimal per orang adalah $7,2 \mathrm{~m}^{2}$. Kondisi infrastruktur yang ada masih belum sesuai dengan standar, dimana sumber air yang ada tercemar dan memiliki warna kekuningan, kondisi sanitasi buruk dan belum memiliki septik tank, pengangkutan sampah belum terjadwal dan banyak ditemukan sampah berserakan di sekitar hunian dan di drainase, serta saluran drainase yang penuh dengan sampah dan limbah serta tertutupi hunian. Ruang publik di Jalan Melayu Tengah terbatas pada ruang jalan dengan lebar 2,4 meter dan drainase dengan lebar 1,5 meter yang diokupansi aktivitas dan hunian penduduk.

Struktur bangunan di Jalan kebanyakan telah mengalami perluasan hunian baik secara vertikal maupun horizontal. Peningkatan secara vertikal sangat jarang yang melebihi 2 lantai. Terdapat juga struktur permanen yang sudah jadi dan dicat, dan banyak dilakukan praktik penggantian material non-permanen menjadi permanen. Terdapat juga hunian yang menggunakan penggabungan material permanen dan non permanen. Hal ini menggambarkan adanya praktik hunian bertahap pada hunian informal di Jalan Melayu Tengah yang dilakukan sesuai dengan kebutuhan dan kemampuan penghuninya tanpa mengikuti standar konstruksi yang ada. Kondisi hunian bertahap yang dilakukan penduduk adalah ekspresi dari kebutuhan spasial yang kurang terpenuhi, sehingga penduduk melakukan peningkatan secara mandiri.

\section{Kesimpulan}

Hunian informal di Jalan Melayu Tengah memiliki kondisi yang tidak sesuai dengan standar dan dapat digolongkan sebagai kawasan yang kumuh. Infrastruktur di sekitar Jalan Melayu Tengah memiliki kondisi yang buruk, dimana jaringan jalan diokupansi hunian penduduk, sumber air tercemar, rumah penduduk belum memiliki septik tank, pengangkutan sampah tidak rutin sehingga terjadi penumpukan sampah di sekitar hunian, serta drainase penuh limbah dan sampah tetapi tidak bisa dibersihkan karena diokupansi hunian penduduk. Kondisi ruang publik yang ada juga tidak sesuai dengan standar, dimana ruang publik di hunian informal Jalan Melayu Tengah terbatas pada ruang jalan, ruang drainase dan ruang fasilitas publik.

Kondisi di hunian informal Jalan Melayu Tengah tersebut diperparah dengan adanya proses peningkatan hunian bertahap yang tidak didasarkan pada standar konstruksi yang ada, melainkan berdasar pada kebutuhan spasial penduduk. Beberapa bentuk hunian bertahap yang dapat berpengaruh pada kondisi kekumuhan di Jalan Melayu Tengah diantaranya yaitu adanya penambahan ruang hunian yang mengokupansi ruang jalan, adanya penambahan bagian baru pada hunian seperti penambahan teras yang mengokupansi ruang drainase. Adanya penggantian material yang kemudian menimbulkan penumpukan material sisa di sekitar rumah yang 
memberikan kesan kotor. Selain itu, hunian penduduk yang terhubung secara langsung dengan jaringan jalan dan drainase telah ditingkatkan secara bertahap telah mengokupansi ruang publik yang ada di sekitarnya. Jenis ruang hunian yang mengokupansi ruang publik diantaranya okupansi ruang dapur, okupansi ruang untuk mengolah makanan, okupansi ruang teras, okupansi ruang MCK, dan okupansi ruang untuk menyimpan barang. Kondisi yang ada di hunian informal di Jalan Melayu Tengah ini sangat mirip dengan apa yang disebutkan dalam penelitian Msimang (2017), hunian informal seringkali mengambil lahan publik untuk memenuhi kebutuhan ruang penghuninya. Hal ini menjadikan ruang publik yang ada tidak bisa dimanfaatkan sebagaimana mestinya, yang berakibat pada buruknya kondisi fasilitas publik di hunian informal. Kondisi yang seperti ini dapat menghasilkan kawasan yang kumuh sebagaimana menurut (Kamalipour \& Dovey, 2020), bahwa proses hunian bertahap dapat menghasilkan kawasan yang kumuh.

\section{Referensi}

Alzamil, W. S. (2018). Evaluating Urban Status Of Informal Settlements In Indonesia: A Comparative Analysis Of Three Case Studies In North Jakarta. Journal Of Sustainable Development, 11(4), 148161.

Bhatt, V., Navarrete, J., Friedman, A., Baharoon, W., Minhu, S., Rubenson, T., \& Wiedemann, S. (1990). How the Other Half Builds. Volume 3: The self-selection process.

Chhetri, N., Stuhlmacher, M., \& Ishtiaque, A. (2019). Nested Pathways to Adaptation. Environmental Research Communications, 1(1), 001-115.

Devi, P. P., Lowry, J. H., \& Weber, E. (2017). Global Environmental Impact Of Informal Settlements And Perceptions Of Local Environmental Threats: An Empirical Case Study In Suva, Fiji. Habitat International, 6(9), 58-67.

Dovey, K. (2015). Sustainable Informal Settlements? Procedia - Social And Behavioral Sciences, 17(9), $125-139$.

Febbiyana, A., \& Suwandono, D. (2016). The Declining Vitality Of Kampung Melayu As The Heritage Area In The City Of Semarang. Jurnal RUANG, 2(4), 341-348.

Hasgül, E. (2016). Incremental Housing: A Participation Process Solution For Informal Housing. Journal Of The Faculty Of Architecture, 13(1), 15-27.

Kamalipour, H., \& Dovey, K. (2019). Mapping The Visibility Of Informal Settlements. Journal of Habitat International, 8(5), 63-75.

Kamalipour, H., \& Dovey, K. (2020). Incremental Production Of Urban Space: A Typology Of Informal Design. Journal of Habitat International, 9(8), 102-133.

Kamalipour, Hesam, \& Dovey, K. (2020). Incremental production of urban space: A typology of informal design. Habitat International, 98(January), 102133. https://doi.org/10.1016/j.habitatint.2020.102133

Kristian, M. K., \& Yuliastuti, N. (2013). Kajian Bentuk Lingkungan Permukiman Berdasarkan Sense Of Comunity Di Kelurahan Dadapsari Semarang. Jurnal Teknik PWK, 2(3), 578-586.

Kustiawan, I., \& Ramadhan, A. (2019). Strategi Peningkatan Kualitas Lingkungan Kampung-Kota Dalam Rangka Pembangunan Kota Yang Inklusif Dan Berkelanjutan: Pembelajaran Dari Kasus Kota Bandung. Journal Of Regional And Rural Development Planning, 3(1), 64-84.

Lombard, M. (2016). Land Conflict In Peri-Urban Areas: Exploring The Effects Of Land Reform On Informal Settlement In Mexico. Urban Studies, 53(13), 2700-2720.

Msimang, Z. (2017). A Study of the Negative Impacts of Informal Settlements on the Environment . A Case Study of Jika Joe , Pietermaritzburg (Master of housing). School of Built Environment and Development Studies: University of KwaZulu-Natal, Howard College Campus. Retrieved from https://researchspace.ukzn.ac.za/bitstream/handle/10413/16293/Msimang_Ziningi_2017.pdf?sequen ce $=1$ \&isAllowed $=y$

Nguluma, H. M. (2003). Housing Themselves: Tranformation, Modernisation And Spatial Qualities In Informal Settlement In Dar Es Salaam, Tanzania. Policy Sciences, 45(2), 123-152.

Saroj, S. K., Goli, S., Rana, M. J., \& Choudhary, B. K. (2019). Availability, Accessibility, And Inequalities Of Water, Sanitation, And Hygiene (Wash) Services In Indian Metro Cities. Sustainable Cities And Society, 5(4), 811-878.

Un-Habitat. (2015). Habitat Iii Issue Papers 22 - Informal Settlements.

Wihardyanto, D., \& Ikaputra, I. (2019). Pembangunan Permukiman Kolonial Belanda Di Jawa : Sebuah Tinjauan Teori. Nature: National Academic Journal Of Architecture, 6(2), 146-159. 